\title{
AOR
}

Selected Papers of \#AolR2019:

The $20^{\text {th }}$ Annual Conference of the Association of Internet Researchers Brisbane, Australia / 2-5 October 2019

\section{THE IMPACT OF ATTITUDES TOWARDS GOVERNMENT AND CORPORATIONS ON TRUST IN TECHNOLOGY}

\author{
Yi-Ning Katherine Chen \\ Department of Advertising, National Chengchi University \\ Chia-Ho Ryan Wen \\ Department of Advertising, National Chengchi University
}

\section{Introduction}

Public fear of emerging technologies in Taiwan is not confined to conspiracies about the government and corporations; people are also worried that scientific experts do not fully expose possible perils, seeing that their research and development are funded largely by either corporations or the government, which inhibits them from fulfilling their responsibility to adequately inform the public. For example, Taiwanese people are concerned that Al will in fact exacerbate unemployment and be used against political dissidents, and also that man-made radio frequency electromagnetic fields (RF-EMF) give rise to cancer and neurological morbidity (Su, 2019). As a result, our study aims to understand the social disjuncture between public opinion and science, looking deeper into the reasons behind the long-term distrust of the government, corporations as well as science community, and discussing the influence of the media

\section{Theoretical Framework}

The theory of motivated reasoning proposes people tend to make conclusions by biasedly selecting and trusting things that reconcile with their previously held viewpoints and political beliefs in particular. When facing controversial issues, people barely assess the relevant facts and evidence rationally. On the contrary, their inherent political beliefs influence how they interpret new information through "selective exposure, attention, comprehension, and recall" (Taber et al., 2009; Nisbet et al., 2015). The contextual thesis argues it is not science itself but how science is employed to greatly uphold policymaking colliding with individuals' identity, values, or interests that repels conservatives. For conservatives, it is "impact science" focusing on proving how cutting-edge techniques are instead holding societies and human beings Suggested Citation (APA): Chen, Y., Wen, C. (2019, October 2-5). The Impact Of Attitudes Towards Government and Corporations on Trust in Technology. Paper presented at AoIR 2019: The $20^{\text {th }}$ Annual Conference of the Association of Internet Researchers. Brisbane, Australia: AolR. Retrieved from http://spir.aoir.org. 
back that they discount. For liberals, it is "production science" dedicated to maximising and optimising the generation and output of industrial products maintaining the modern lifestyle that they distrust.

Furthermore, while media act as a bridge where the public can approach science community and get to know their research, the divide of ideology and trust is increasingly being widened along the way from the beginning where the media report science as well as simultaneously frame stories in accordance with their ideological stances, to audiences selecting the preferred media aligned with their ideology to access scientific issues, and finally to the end where audiences decide whether the scientists and the science are trustworthy by judging if they recognise their values through the lens of media (Feldman et al., 2012; Dunlap \& McCright, 2011). Media effects on public perceptions of science are salient. Excessive emphasis on the downsides of certain sciences placed by media could be a heavy blow to public trust in science.

Finally, research of user behaviour commonly considers personality traits to be useful predictors. One of the widely employed tools for analysing personality traits in relation to media usage is the Five-Factor Model raised by Costa and McCrae (2008): agreeableness, openness to experience, neuroticism, conscientiousness, and extraversion. Existing communication research shows that the model has principally been utilised to investigate social media usage, accompanied by demographic analyses. Additionally, among the five dimensions, openness to experiences, neuroticism, and extraversion have been recognised as relatively salient predictors of social media usage by several pieces of online behaviour research (Tan \& Yang, 2014; Correa et al., 2010; Zywica \& Danowski, 2008).

Based on the aforementioned concepts and theories, we present the following hypotheses and questions.

$\mathrm{H} 1$ : Trust in the government is positively associated with a) trust in RF-EMF, b) trust in the RF-EMF science community, c) trust in Al, and d) trust in the Al science community.

$\mathrm{H} 2$ : Trust in corporations is positively associated with a) trust in RF-EMF, b) trust in the RF-EMF science community, c) trust in $\mathrm{Al}$, and d) trust in the $\mathrm{Al}$ science community.

RQ1: Does attention to general news affect trust in the government, trust in corporations, trust in RF-EMF, trust in the RF-EMF science community, trust in $\mathrm{Al}$, and trust in the $\mathrm{Al}$ science community?

RQ2: Does attention to political news affect trust in the government, trust in corporations, trust in RF-EMF, trust in the RF-EMF science community, trust in $\mathrm{Al}$, and trust in the $\mathrm{Al}$ science community?

RQ3: Does attention to scientific news affect trust in the government, trust in corporations, trust in RF-EMF, trust in the RF-EMF science community, trust in 
$\mathrm{Al}$, and trust in the $\mathrm{Al}$ science community?

RQ4: Do personality traits influence attention to news, trust in corporations, trust in the government, trust in scientific techniques (RF-EMF/AI), and trust in the (RF-EMF/AI) science community?

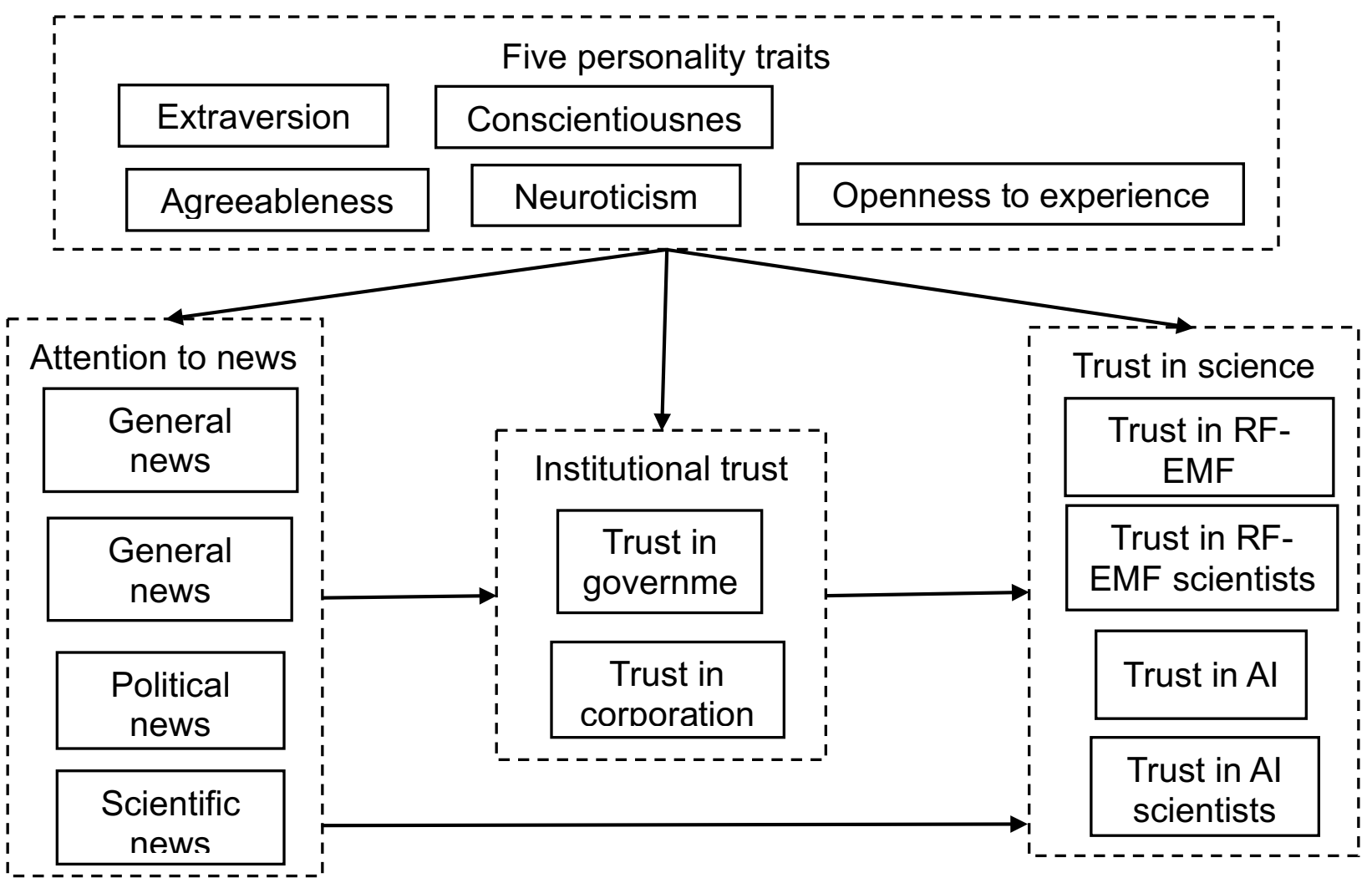

Figure 1. Research model

\section{Results}

By judgemental sampling, our survey was disseminated online between April 29 and May 17 in 2019 via Facebook and Dcard. After deducting unfinished and unqualified feedbacks, valid feedbacks amount to 1009 , with $52 \%$ from females and $48 \%$ from males. The average age is $28(S D=8.35)$.

Our findings demonstrate that the respondents have discrepant levels of trust when it comes to the two sciences (RF-EMF and $\mathrm{Al}$ ) and the science community developing them. Second, government trust and corporation trust in general encourage participants to trust both science and its community. Third, mediation effects, with government trust and corporation trust as mediators, are sought with general news and political news attention, but not with scientific news attention. Fourth, general news attention mitigates science trust, while scientific news attention increases it. Finally, political news attention has no significant influences on science trust, when government trust and corporation trust are not acting as mediators. 


\section{References}

Correa, T., Hinsley, A. W., \& De Zuniga, H. G. (2010). Who interacts on the Web?: The intersection of users' personality and social media use. Computers in Human Behavior, 26(2), 247-253.

Costa, P. T., \& McCrae, R. R. (2008). The revised neo personality inventory (neo-pi-r). The SAGE Handbook of Personality Theory and Assessment, 2(2), 179-198.

Dunlap, R. E., \& McCright, A. M. (2011). Organized climate change denial. The Oxford Handbook of Climate Change and Society, 1, 144-160.

Feldman, L., Maibach, E. W., Roser-Renouf, C., \& Leiserowitz, A. (2012). Climate on cable: The nature and impact of global warming coverage on Fox News, CNN, and MSNBC. The International Journal of Press/Politics, 17(1), 3-31.

Nisbet, E. C., Cooper, K. E., \& Ellithorpe, M. (2015). Ignorance or bias? Evaluating the ideological and informational drivers of communication gaps about climate change. Public Understanding of Science, 24(3), 285-301.

Su, K. P. (2019, May 22). Preventing Al abuse requires cooperation. Taipei Times, p. 8.

Taber, C. S., Cann, D., \& Kucsova, S. (2009). The motivated processing of political arguments. Political Behavior, 31(2), 137-155.

Tan, W. K., \& Yang, C. Y. (2014). Internet applications use and personality. Telematics and Informatics, 31(1), 27-38.

Zywica, J., \& Danowski, J. (2008). The faces of Facebookers: Investigating social enhancement and social compensation hypotheses; predicting Facebook ${ }^{\mathrm{TM}}$ and offline popularity from sociability and self-esteem, and mapping the meanings of popularity with semantic networks. Journal of Computer-Mediated Communication, 14(1), 1-34. 